\title{
Oxidative coupling and dechlorination of aromatic compounds on modified activated carbon
}

\author{
Masaru Iwanaga $^{\text {a),*}, \text { Yoshimasa Amano }}{ }^{\text {a),b) }}$, Masami Aikawa ${ }^{\text {c) }}$ and Motoi Machida ${ }^{\text {a),b) }}$
}

\begin{abstract}
Dechlorination by oxidative coupling during the adsorption of mono-chlorophenols (mono-CPs) onto activated carbon (AC) was investigated, and the effects of various parameters such as amount of dissolved oxygen, surface structure and temperature of solution on dechlorination amount were examined. Under anoxic conditions, the amounts of adsorption and dechlorination for mono-CPs decreased compared to conditions where oxygen is present. This result indicated that the oxidative coupling would depend on dissolved oxygen. It is known that dissolved oxygen was transformed into reactive oxygen species on the AC surface. Therefore, we propose that reactive oxygen species originating from dissolved oxygen react with chlorophenol, causing dechlorination and the oxidative coupling by radical reaction. The introduction of pyrrole- and/or pyridine-like structures in the carbon by $\mathrm{NH}_{3}$ gas treatment at temperatures above $700{ }^{\circ} \mathrm{C}$ promoted the reduction of dissolved oxygen, which caused the increase in the amount of dechlorination. On the other hand, $\mathrm{HNO}_{3}$ oxidation of $\mathrm{AC}$ noticeably decreased the amount of dechlorination, indicating that the acidic functional groups possessing an electron-withdrawing ability inhibited the reduction of dissolved oxygen on the AC surface. It was also found that the amount of dechlorination and its rate were influenced by the temperature of the solution.
\end{abstract}

KEYWORDS: Activated carbon, Chlorophenol, Oxidative coupling, Dissolved oxygen, Dechlorination reaction

\section{Introduction}

Chlorophenols (CPs) are well known as typical pollutant discharged from various kinds of industries because of high toxicity and low biodegradability. It is also known that mono-chlorophenols (mono-CPs) causes the formation of dioxins via phenoxyl radical at high temperature ${ }^{1)}$. The methods of CPs removal in waste water is extensively studied, e.g. adsorption by activated carbon $(\mathrm{AC})^{2), 3)}$ and so on. AC has been widely used to remove aromatic compounds because of large surface area attributed to the pore structure and strong affinity due to the $\pi-\pi$ interaction between AC surface and adsorbate. Therefore, many studies investigated the effect of various parameters on the removal of harmful aromatic compounds ${ }^{2), 3)}$.

Recent studies revealed that phenolic compounds were polymerized on the AC surface via "oxidative coupling"(6)-11), and that the oxidative coupling of phenolic compounds caused the irreversible adsorption and the increase in adsorption amount ${ }^{7)-10)}$. Zeid et al. and Pimenta et al. conducted the phenol adsorption experiment and found that 2,2-dihydroxy-1,1-biphenyl, 4-phenoxyphenol and a trimer were detected in the extraction of methanol and methylene chloride using the $\mathrm{AC}$ after the adsorption experiment ${ }^{(6), 8)}$. On the other hand, it is known that the oxidative coupling is related to the carboxylic groups, which represent strong inhibition for the reaction ${ }^{9)}$. Vidic et al. concluded that the oxygen containing acidic surface functional groups hindered the oxidative coupling and the oxygen containing basic surface functional groups (e.g., pyrone-type) was the key factor in promoting the reaction of oxidative coupling ${ }^{7)}$. Furthermore, it was clarified that the ash and metal in AC had no influence on the oxidative coupling ${ }^{7}$. Thus, there are several studies on the oxidative coupling in the adsorption of phenolic compounds, but the detailed mechanisms, e.g. the role of dissolved oxygen, the effects of AC surface structure and temperature of solution, have not been well understood. In particular, the role of dissolved oxygen on the AC surface is considered as one of the key factors in the oxidative coupling.

Several studies reported that the oxidative coupling depended on the dissolved oxygen and was inhibited under anoxic condi-

* Corresponding Author, E-mail: liver_pool_owen10@yahoo.co.jp 
tions ${ }^{6), 7), 99,10)}$. Activated carbon shows the catalytic activity to the oxygen reduction reaction (ORR) and causes the generation of reactive oxygen species ${ }^{12)-16}$. It is known that the adsorption process of $\mathrm{O}_{2}$ is the first step of ORR on carbon-based catalyst ${ }^{16)}$. Recent studies reported that the nitrogen-doped carbon catalyst showed the strong adsorption ability of $\mathrm{O}_{2}$ and activity to the $\mathrm{ORR}^{13), 15), 16)}$. The detailed mechanism of ORR has not been well understood, but Woods et al. suggested the possibility that pyridinic nitrogen became a part of the ORR active site ${ }^{15)}$. Niwa et al. also reported that carbon atom beside to graphite-like nitrogen at zig-zag edge was the ORR active site ${ }^{16)}$. These reports indicate that nitrogen-doped $\mathrm{AC}$ has the strong reduction and adsorption ability of dissolved oxygen which is involved in the oxidative coupling in this study.

The objective of this study is to clarify the role of dissolved oxygen in the oxidative coupling. Adsorption, desorption and dechlorination amounts of mono-CPs were measured under oxic or anoxic conditions. Also, the effect of different surface structure (AC possessing the pyrrol- and/or pyridine-like structure or the acidic functional groups), adsorbate and temperature were inspected to elucidate detailed reaction mechanism of oxidative coupling and dechlorination reaction.

\section{Materials and Methods}

\subsection{Activated carbon}

Commercially available coal pitch-based activated carbon (AC), Filtrasorb 400 (F400), was purchased from Calgon Carbon Japan. Removal of ash content in F400 was carried out using $2 \mathrm{M} \mathrm{HCl}$ and $\mathrm{HF}$ (46\%). After de-ashing, F400 was washed in boiled de-ionized water and dried at $110^{\circ} \mathrm{C}$ (F400-DA: De-ashing). F400-DA was placed in a quartz tube and heated to $1000{ }^{\circ} \mathrm{C}$ under He flow and temperature was kept for 60 minutes to remove the surface functional groups (F400-OG: Outgassing). $\mathrm{NH}_{3}$ gas treatment for F400-DA was carried out to introduce nitrogen atom into carbon frame as following procedure. F400-DA was placed in a quartz tube and heated to 700, 800, 900 or $1000{ }^{\circ} \mathrm{C}$ under He flow of $150 \mathrm{~mL} / \mathrm{min}$. After the quartz tube containing F400-DA was heated to desired temperature, He gas was switched to $\mathrm{NH}_{3}$ gas $(99.999+\%)$. The samples were kept for 60 minutes under $\mathrm{NH}_{3}$ gas flow $(250 \mathrm{~mL} / \mathrm{min})$ and then cooled to $500{ }^{\circ} \mathrm{C}$. When the temperature dropped to $500{ }^{\circ} \mathrm{C}, \mathrm{NH}_{3}$ gas was switched to $\mathrm{He}$ and kept for 30 minutes to completely remove the-remaining $\mathrm{NH}_{3}$ in the system (F400-xAG: Ammonia-gas treatment at $700-1000{ }^{\circ} \mathrm{C}$, e.g., $800^{\circ} \mathrm{C}$ for $\left.8 \mathrm{AG}\right)^{17)}$. For the oxidation treatment, F400-DA was oxidized by $8 \mathrm{M} \mathrm{HNO}_{3}$ at $90{ }^{\circ} \mathrm{C}$ for 6 hours. After oxidation, F400DA was washed in boiled de-ionized water, dried at $110^{\circ} \mathrm{C}$ and heated at $350{ }^{\circ} \mathrm{C}$ for 4 hours to remove the residual nitrate ions on $\mathrm{AC}$ (F400-OX: Oxidation)

\subsection{Structure properties}

The specific surface area and the pore volume distribution were measured by a SA3100 (Beckman Coulter, USA). The sample tube containing each activated carbon was degassed at $300^{\circ} \mathrm{C}$ for 90 minutes in vacuum. After degassing, the sample tube was immersed in liquid nitrogen. The value of specific surface area and pore volume distribution were obtained from the adsorption isotherm of nitrogen at liquid nitrogen temperature $\left(-196^{\circ} \mathrm{C}\right)$. The isotherm was analyzed by the subtracting pore effect (SPE) method using $\alpha_{\mathrm{s}}$ plot to figure out the specific surface area and micro pore volume ${ }^{18), 19)}$.

\subsection{Elemental analysis}

Elemental analysis was performed by Perkin-Elmer 2400 (PerkinElmer, Japan). The powdered activated carbon (AC) sample in a tin capsule was dried at $110^{\circ} \mathrm{C}$ and burned out at $980{ }^{\circ} \mathrm{C}$. The carbon and hydrogen contents were determined by measuring $\mathrm{CO}_{2}$ and $\mathrm{H}_{2} \mathrm{O}$, respectively. Nitrogen content was determined measuring $\mathrm{N}_{2}$ obtained by reduction of generated $\mathrm{NO}_{x}$. The oxygen content was calculated by substituting the summation of $\mathrm{C}, \mathrm{H}$ and $\mathrm{N}$ contents from 100 based on the assumption that $\mathrm{AC}$ was composed of only $\mathrm{C}, \mathrm{H}, \mathrm{O}$ and $\mathrm{N}$

\subsection{Surface characterization}

Boehm titration was applied to evaluate the acidic (carboxylic, lactonic and phenolic groups) and basic functional groups of each activated carbon (AC). A $500 \mathrm{mg} \mathrm{AC}$ was added to $0.1 \mathrm{~mol} / \mathrm{L} \mathrm{NaOH}$, $\mathrm{NaHCO}_{3}, \mathrm{HCl}$ or $0.05 \mathrm{~mol} / \mathrm{L} \mathrm{Na}_{2} \mathrm{CO}_{3}$, and agitated for 5 days. The acidic and basic functional groups were respectively determined by titrating $0.06 \mathrm{~mol} / \mathrm{L} \mathrm{HCl}$ and $0.1 \mathrm{~mol} / \mathrm{L} \mathrm{NaOH}^{20)}$.

The $\mathrm{pH}$ of the point of zero charge $\left(\mathrm{pH}_{\mathrm{pzc}}\right)$ indicates the surface condition of $\mathrm{AC}$ with no positive/negative charge at particular $\mathrm{pH}$ in solution. Initial $\mathrm{pH}$ was adjusted by $0.1 \mathrm{~mol} / \mathrm{L} \mathrm{HCl}$ and/or $\mathrm{NaOH}$ in the range from 2 to 12 . A $100 \mathrm{mg} \mathrm{AC}$ was added to $50 \mathrm{~mL}$ different $\mathrm{pH}$ solution and agitated for 3 days. Equilibrium $\mathrm{pH}$ was measured by $\mathrm{pH}$ meter (D51, Horiba, Japan) and was plotted versus initial $\mathrm{pH}$. $\mathrm{pH}_{\mathrm{pzc}}$ was the point which had equal $\mathrm{pH}$ for both the initial and the equilibrium states ${ }^{21)}$.

\subsection{Thermogravimetric analysis}

Thermogravimetric analysis was performed by EXSTAR6000 TG/ DTA6200 (Seiko Instruments, Japan). F400-OG before and after the adsorption of 4-chlorophenol were dried at $180{ }^{\circ} \mathrm{C}$ under $\mathrm{He}$ gas flow for 30 minutes. Each sample was put in a small cylindrical aluminum container and placed on a platinum plate equipped with the TG/DTA weighing system. A $10 \mathrm{mg}$ of activated carbon was heated at $10^{\circ} \mathrm{C} /$ min up to $1000^{\circ} \mathrm{C}$ under $\mathrm{He}$ gas flow at $130 \mathrm{~mL} / \mathrm{min}$.

\subsection{Adsorption and desorption experiment}

Activated carbon (AC) was dosed into 2-chlorophenol, 3-chlorophenol or 4-chlorophenol solution $(10.0 \mathrm{mmol} / \mathrm{L})$ with the proportion of $100 \mathrm{mg} \mathrm{AC}$ to $50 \mathrm{~mL}$ solution and agitated at $100 \mathrm{rpm}$ for 7 days at $25^{\circ} \mathrm{C}$. After adsorption of each chlorophenol, the test solution was removed by decantation. The extraction for each $\mathrm{AC}$ was performed by methanol for 1 day to determine the desorption amount of ad- 
sorbed chlorophenol or by $\mathrm{NaOH}$ aq. at $\mathrm{pH} 10$ for 1 day to measure the dechlorination amount. Adsorbate concentration was determined by UV/Vis spectrophotometer (UV-2550, Shimadzu, Japan). Equilibrium adsorption amount $\left(Q_{\mathrm{e}}, \mathrm{mmol} / \mathrm{g}\right)$ was calculated by following equation.

$$
Q_{\mathrm{e}}=\frac{\left(C_{0}-C_{\mathrm{e}}\right) \times V}{M}
$$

where $C_{0}$ and $C_{\mathrm{e}}$ are the initial and equilibrium concentration of adsorbate $(\mathrm{mmol} / \mathrm{L})$ in aqueous solution, respectively. $V(\mathrm{~L})$ is the volume of solution and $M(\mathrm{~g})$ is the weight of the AC.

Desorption amount $\left(Q_{\mathrm{d}}, \mathrm{mmol} / \mathrm{g}\right)$ was calculated by following equation.

$$
Q_{\mathrm{d}}=\frac{C_{\mathrm{m}} \times V}{M}
$$

where $C_{\mathrm{m}}$ is the concentration of adsorbate $(\mathrm{mmol} / \mathrm{L})$ in methanol solution.

Irreversible adsorption amount $\left(Q_{\mathrm{ir}}, \mathrm{mmol} / \mathrm{g}\right)$ which represented the residual chlorophenols on $\mathrm{AC}$ surface after methanol extraction was calculated by following equation.

$$
Q_{\text {ir }}=Q_{\mathrm{e}}-Q_{\mathrm{d}}
$$

\subsection{Estimation of dechlorination reaction}

Dechlorination amount was calculated by measuring the chloride ions in the adsorption and desorption solution. Concentration of chloride ions in the solution was determined by ion chromatography (ICS-1100, Dionex, USA). The dechlorination amount (DC, mmol/g) was calculated by following equation.

$$
D C=\frac{V}{M}\left(C_{\mathrm{a}}+C_{\mathrm{d}}\right)
$$

where $C_{\mathrm{a}}$ and $C_{\mathrm{d}}$ are the concentration of chloride ion in the adsorption and desorption solution at $\mathrm{pH} 10$ which was adjusted by $\mathrm{NaOH}$ aq., respectively.

The detailed methods to prepare the anoxic condition of the reaction solution were as follows. Firstly, each conical flask containing $\mathrm{CP}$ solution and $\mathrm{AC}$ was bubbled by $\mathrm{N}_{2}$ gas over 5 minutes to remove the dissolved oxygen. Each flask was tightly sealed by cap, then each was placed in thick polyethylene bags with a deoxidizer and agitated at $100 \mathrm{rpm}$ for 7 days at $25^{\circ} \mathrm{C}$.

The influence of solution temperature was investigated by controlling temperature from 5 to $45^{\circ} \mathrm{C}$, respectively.

\subsection{Statistical analysis}

The experiments investigating the effects of different adsorbate and adsorbent were performed in triplicates. The statistical difference between two categories was tested with one-way analysis of variance (ANOVA) followed by two-sided Student's $t$-test. Multiple compari- sons between groups were made by one-way ANOVA first, and then analyzed by Tukey's HSD test. Difference was considered to be significant when $p<0.05$. All statistical tests were performed using SPSS 19 windows version (IBM, USA).

\section{Results and Discussion}

\subsection{The role of dissolved oxygen}

Table 1 shows adsorption, desorption, irreversible adsorption and dechlorination amounts of 2-chlorophenol (2-CP), 3-chlorophenol (3-CP) and 4-chlorophenol (4-CP) on F400-OG under oxic or anoxic conditions, respectively. Under anoxic conditions, adsorption, irreversible adsorption and dechlorination amounts of all adsorbate decreased compared to those under oxic conditions $(p<0.05)$. This result shows that the oxidative coupling and dechlorination reaction is inhibited under anoxic conditions, of which the trend is consistent with the results of phenolic compounds (chlorophenols etc.) observed by several studies ${ }^{6,9), 10)}$. On the other hand, the adsorption of aliphatics such as trichloromethane showed constant amount under both oxic and anoxic conditions ${ }^{6}$. On the activated carbon (AC) surface, adsorbed dissolved oxygen is converted to reactive oxygen spe$\operatorname{cies}^{12)-14)}$. Vidic et al. proposed that the oxidative coupling of phenols progressed via phenoxyl radical. In this study, the oxidative coupling was inhibited under anoxic conditions. This result suggests that reactive oxygen species generated on AC surface involve in the generation of phenoxyl radical ${ }^{7}$. Phenoxyl radical reacts with AC surface and causes a covalent binding with $\mathrm{AC}$ surface via dechlorination reaction. Also, the coupling reaction between phenoxyl radicals leads to the dimmer (diphenylether, dihydroxybiphenyl) ${ }^{6), 8), 22), 23)}$.

\subsection{Different adsorbate}

Desorption ratio and irreversible adsorption shown in Table 1 represents the reactivity of each chlorophenol to oxidative coupling. In the process of oxidative coupling, irreversible adsorption of phenolic compounds is caused by covalent binding of phenoxyl radical to activated carbon (AC) surface and by generation of oxidative coupling products in the micro pore ${ }^{8)}$. The result in this study shows that 2-chlorophenol (2-CP) had the highest reactivity to oxidative coupling, whereas the lowest reactivity was obtained for 3-chlorophenol (3-CP). Vidic et al. pointed out that the difference in reactivity to oxidative coupling was due to the difference in homolytic bond dissociation energies (BDE) for the $\mathrm{O}-\mathrm{H}$ bounds of phenolic compounds $^{5)}$. The BDE values of 2-CP, 3-CP and 4-chlorophenol (4-CP) were estimated as $90.0,91.8$ and $90.3 \mathrm{kcal} / \mathrm{mol}$, respectively ${ }^{24)}$. These values reveal that 3-CP shows the lowest reactivity, which indicates more difficult state to form phenoxyl radical. This finding supports the results obtained in this study.

Figs. 1(a) and (b) show the results of TG/DTA analysis for F400OG before and after the 4-CP adsorption, respectively. The large peaks of weight loss in Fig. 1(b) were observed at $251^{\circ} \mathrm{C}$ and $616^{\circ} \mathrm{C}$. 
Table 1 Adsorption, desorption and dechlorination amounts of mono-CPs on F400-OG.

\begin{tabular}{|c|c|c|c|c|c|c|}
\hline & \multicolumn{3}{|c|}{ Oxic condition } & \multicolumn{3}{|c|}{ Anoxic condition } \\
\hline & $2-\mathrm{CP}$ & $3-\mathrm{CP}$ & $4-\mathrm{CP}$ & $2-\mathrm{CP}$ & $3-\mathrm{CP}$ & 4-CP \\
\hline Adsorption amount, $\mathrm{mmol} / \mathrm{g}$ & $3.39 \pm 0.06$ & $3.24 \pm 0.09$ & $3.23 \pm 0.07$ & $3.18 \pm 0.04$ & $2.95 \pm 0.06$ & $2.97 \pm 0.05$ \\
\hline Desorption amount, $\mathrm{mmol} / \mathrm{g}$ & $1.70 \pm 0.01$ & $2.27 \pm 0.01$ & $2.12 \pm 0.04$ & $2.43 \pm 0.06$ & $2.44 \pm 0.05$ & $2.63 \pm 0.05$ \\
\hline Desorption ratio $^{\mathrm{a}}, \%$ & $49.5 \pm 0.4$ & $71.3 \pm 0.8$ & $64.4 \pm 0.6$ & $76.2 \pm 1.4$ & $83.0 \pm 0.4$ & $87.7 \pm 2.3$ \\
\hline $\begin{array}{l}\text { Irreversible adsorption amount }{ }^{\mathrm{b}} \text {, } \\
\mathrm{mmol} / \mathrm{g}\end{array}$ & $1.73 \pm 0.04$ & $0.92 \pm 0.04$ & $1.17 \pm 0.03$ & $0.76 \pm 0.04$ & $0.50 \pm 0.02$ & $0.37 \pm 0.07$ \\
\hline Dechlorination amount, $\mu \mathrm{mol} / \mathrm{g}$ & $9.69 \pm 0.15$ & $5.80 \pm 0.21$ & $191 \pm 16$ & $1.40 \pm 0.35$ & $2.41 \pm 1.45$ & $14.3 \pm 2.2$ \\
\hline Dechlorination ratio ${ }^{\mathrm{c}}, \%$ & $0.29 \pm 0.00$ & $0.17 \pm 0.06$ & $6.00 \pm 0.50$ & $0.04 \pm 0.01$ & $0.08 \pm 0.05$ & $0.49 \pm 0.08$ \\
\hline
\end{tabular}

Initial concentration of adsorbate: $10.0 \mathrm{mmol} / \mathrm{L}$, Adsorption time: 7 days ${ }^{\mathrm{a}}$ Calculated by (Desorption amount)/(Adsorption amount) $\times 100 \quad{ }^{\mathrm{b}}$ Calculated by (Adsorption amount) $-\left(\right.$ Desorption amount) ${ }^{\mathrm{c}}$ Calculated by (Dechlorination amount)/(Adsorption amount) $\times 100$

The first peak at $251{ }^{\circ} \mathrm{C}$ relates to the release of physisorbed 4-CP (boiling point $=220^{\circ} \mathrm{C}$ ) by $\pi-\pi$ interaction. On the other hand, the second peak at $616^{\circ} \mathrm{C}$ is attributed to chemisorbed 4-CP by the covalent binding of phenoxyl radical to AC surface. Same behaviors for 2-CP and 3-CP were observed by Maroto-Valer et al. ${ }^{25)}$, who concluded that the peak around $620^{\circ} \mathrm{C}$ was attributed to chemisorbed 2-CP and 3-CP on AC.

Dechlorination amount of mono-CPs using F400-OG under oxic conditions is shown in Table 1. Dechlorination amount was followed in the decreasing order of $4-\mathrm{CP}>2-\mathrm{CP}>3-\mathrm{CP}(p<0.05)$. The variation in dechlorination amount is due to the difference of chlorine-substituted position of mono-chlorophenols (mono-CPs). From the values of desorption ratio and dechlorination amounts, mono-CPs would make a chemical bond with $\mathrm{AC}$ at para position, causing the highest dechlorination amount of 4-CP. In the case of 3-CP the unpaired electron of free radical was not located at a chlorine-substituted position, causing the lowest amount of dechlorination ${ }^{11), 22)}$. Also, the lowest reactivity of 3-CP would be due to the steric barrier of chlorine atom presented in meta position. Methanol extraction could not recover full amount of non-chemisorbed mono-CPs. Therefore, irreversible adsorption amount was not equal to the amount of dechlorination in

Table 1. These results reveal that the position of substituent group affects the dechlorination reaction.

\section{3 $\mathrm{NH}_{3}$ gas treatment}

Table 2 gives the result of yields, specific surface areas $\left(S_{\alpha \mathrm{s}}\right)$, pore distributions ( $V_{\text {total }}, V_{\text {micro }}$ and $\left.V_{\text {meso }}\right)$, meso pore ratios $\left(r_{\alpha \text { meso }}\right)$ and average pore diameters $\left(D_{\text {pore }}\right)$, and Table 3 shows the result of elemental compositions for each activated carbon (AC), respectively. Each parameter of $S_{\alpha \mathrm{s}}, V_{\text {meso }}, r_{\text {meso }}, D_{\text {pore }}$ and nitrogen content increased with increasing $\mathrm{NH}_{3}$ gas treatment temperature, but the increase in temperature caused the decrease in yield. At $900{ }^{\circ} \mathrm{C}$, activated carbon reacts with $\mathrm{NH}_{3}$, and generates $\mathrm{CH}_{4}{ }^{26)}$.

$$
3 \mathrm{C}+4 \mathrm{NH}_{3} \rightarrow 3 \mathrm{CH}_{4}+2 \mathrm{~N}_{2}
$$

Sthör and Boehm reported that BET surface area and meso pore volume were increased by $\mathrm{NH}_{3}$ gas treatment at $900{ }^{\circ} \mathrm{C}^{14)}$. $\mathrm{NH}_{3}$ reacts
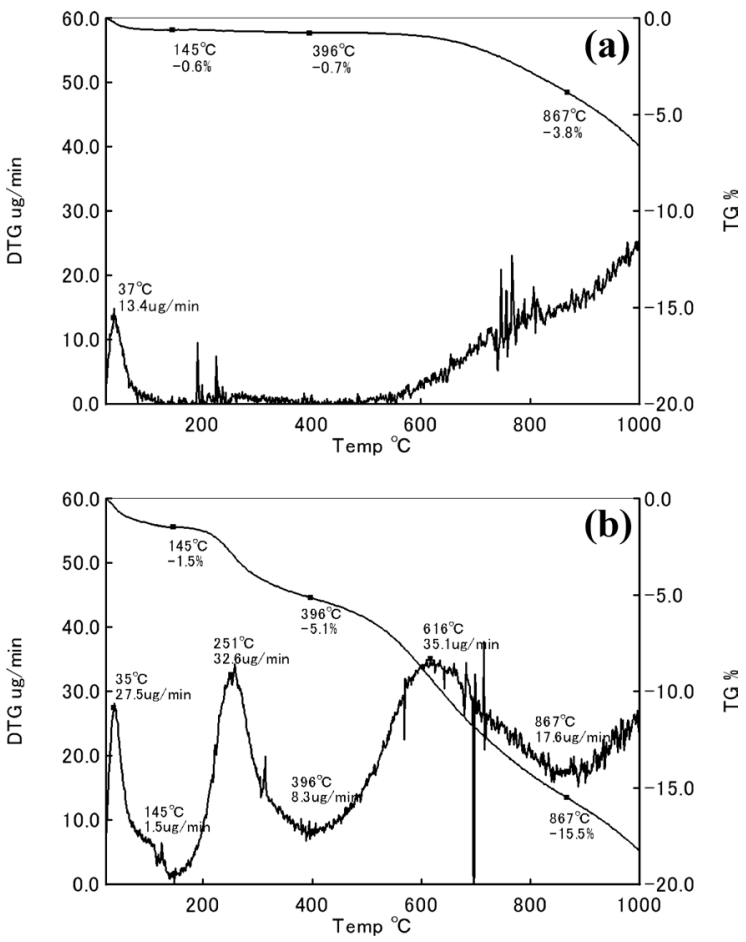

Fig. 1 TG/DTA analysis of (a) F400-OG and (b) F400-OG after 4-CP adsorption.

with the surface functional groups such as carboxylic, phenolic and ether-like oxygen of AC leading to amide, nitrile and pyridine-like structure ${ }^{12), 14), 27)}$. This process generates $\mathrm{H}_{2} \mathrm{O}$, which would act as an activating agent at high temperature ${ }^{28)}$.

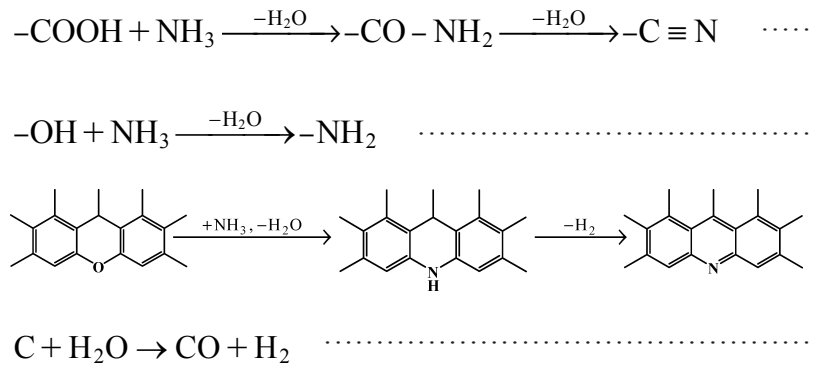

In the process of $\mathrm{NH}_{3}$ gas treatment, amide, imide, imine, amine and nitrile groups tend to dominate below $600^{\circ} \mathrm{C}$, while the domi- 
Table 2 Yields and structure properties of the prepared activated carbons.

\begin{tabular}{|c|c|c|c|c|c|c|c|}
\hline & Yield, \% & $S_{\alpha \mathrm{s}}, \mathrm{m}^{2} / \mathrm{g}$ & $V_{\text {total }}, \mathrm{cm}^{3} / \mathrm{g}$ & $V_{\text {micro }}, \mathrm{cm}^{3} / \mathrm{g}$ & $V_{\text {meso }}, \mathrm{cm}^{3} / \mathrm{g}$ & $r_{\alpha \text { meso }}, \%$ & $D_{\text {pore }}, \AA$ \\
\hline F400-DA ${ }^{\mathrm{a}}$ & - & 1227 & 0.63 & 0.44 & 0.19 & 29.7 & 7 \\
\hline $\mathrm{F} 400-\mathrm{OG}^{\mathrm{b}}$ & 96.7 & 1220 & 0.61 & 0.43 & 0.18 & 29.5 & 7 \\
\hline $\mathrm{F} 400-7 \mathrm{AG}^{\mathrm{c}}$ & - & 1421 & 0.63 & 0.45 & 0.18 & 28.8 & 7 \\
\hline $\mathrm{F} 400-8 \mathrm{AG}^{\mathrm{c}}$ & 97.5 & 1439 & 0.66 & 0.46 & 0.20 & 29.9 & 7 \\
\hline F400-9AG & 78.3 & 1563 & 0.88 & 0.59 & 0.29 & 32.8 & 9 \\
\hline $\mathrm{F} 400-10 \mathrm{AG}^{\mathrm{c}}$ & 44.6 & 1610 & 1.13 & 0.75 & 0.39 & 34.2 & 11 \\
\hline $\mathrm{F} 400-\mathrm{OX}^{\mathrm{d}}$ & 86.2 & 951 & 0.63 & 0.41 & 0.22 & 35.5 & 10 \\
\hline
\end{tabular}

${ }^{\mathrm{a}} \mathrm{DA}$ : De-Ashing by $2 \mathrm{M} \mathrm{HCl}$ and $\mathrm{HF}(46 \%) \quad{ }^{\mathrm{b}} \mathrm{OG}$ : Outgassing of F400-DA in He flow at $1000^{\circ} \mathrm{C} \quad{ }^{\mathrm{c}} x \mathrm{AG}$ : Ammonia gas treatment of F400-DA at 700 $1000{ }^{\circ} \mathrm{C}$, e.g. $800{ }^{\circ} \mathrm{C}$ for $8 \mathrm{AG}{ }^{\mathrm{d}} \mathrm{OX}: 8 \mathrm{M} \mathrm{HNO}_{3}$ treatment of $\mathrm{F} 400$-DA at $90{ }^{\circ} \mathrm{C}$

Table 3 Elemental compositions, adsorption and dechlorination amounts of 4-chlorophenol on various activated carbons.

\begin{tabular}{|c|c|c|c|c|c|c|}
\hline & $\mathrm{C}$ & $\mathrm{H}$ & $\mathrm{N}$ & $\mathrm{O}^{\mathrm{a}}$ & \multirow{2}{*}{$\begin{array}{l}\text { Adsorption amount, } \\
\mathrm{mmol} / \mathrm{g}\end{array}$} & \multirow{2}{*}{$\begin{array}{l}\text { Dechlorination } \\
\text { amount, } \mathrm{mmol} / \mathrm{g}\end{array}$} \\
\hline & \multicolumn{4}{|c|}{$\mathrm{mmol} / \mathrm{g}$} & & \\
\hline F400-DA & 78.2 & 0.3 & 0.3 & 3.6 & $3.01 \pm 0.08$ & $0.130 \pm 0.005$ \\
\hline F400-OG & 80.0 & 0.0 & 0.3 & 2.2 & $3.23 \pm 0.07$ & $0.191 \pm 0.016$ \\
\hline F400-7AG & 78.2 & 1.1 & 1.2 & 2.8 & $3.41 \pm 0.07$ & $0.209 \pm 0.007$ \\
\hline F400-8AG & 77.7 & 0.7 & 1.6 & 2.7 & $3.39 \pm 0.05$ & $0.238 \pm 0.005$ \\
\hline F400-9AG & 76.8 & 1.2 & 2.7 & 2.5 & $3.72 \pm 0.05$ & $0.301 \pm 0.010$ \\
\hline F400-10AG & 76.9 & 1.3 & 2.5 & 2.6 & $4.04 \pm 0.01$ & $0.407 \pm 0.042$ \\
\hline F400-OX & 68.8 & 0.7 & 0.8 & 10.2 & $2.06 \pm 0.02$ & $0.004 \pm 0.001$ \\
\hline
\end{tabular}

Initial concentration of 4-CP: $10.0 \mathrm{mmol} / \mathrm{L}$, adsorption time: 7 days ${ }^{\mathrm{a}}$ Calculated by difference

nance of pyrrol- and/or pyridine-like structure on the AC surface are observed above $600{ }^{\circ} \mathrm{C}^{27)}$. It is also represented that amide, imide, lactam, secondary amide and $\mathrm{N}$-alkyl amide groups are incorporated into aromatic surface structures in the form of pyrrol- and/or pyridine-like structure at high temperature ${ }^{29)}$. These results indicated that $\mathrm{NH}_{3}$ gas treatments for the $\mathrm{AC}$ at high temperature in this study caused pyrrol- and/or pyridine-like structure on the AC surface.

Table 3 provides the results of adsorption and dechlorination amount of 4-chlorophenol (4-CP) and elemental analysis for the ACs. The increases in nitrogen content, adsorption and dechlorination amounts were observed with increasing $\mathrm{NH}_{3}$ gas treatment temperature. In particular, F400-10AG showed advantage for adsorption and dechlorination amount of 4-CP compared to the other adsorbents $(p<0.05)$. Phenolic compounds are flatly adsorbed on the AC surface by the $\pi-\pi$ interaction occurred between the basal plane of AC surface and $\pi$ electron of phenolic compounds ${ }^{2}$. Therefore, the increase in adsorption amount would be in proportion to surface area of ACs.

The increase in dechlorination amount in Table $\mathbf{3}$ is correlated with the increase in nitrogen content of AC. In the oxygen reduction reaction (ORR), nitrogen in carbon frame (pyrrol- and/or pyridinelike structure) promotes the ORR activity of carbon-based catalysts ${ }^{13), 15), 16}$. These results indicate that $\mathrm{NH}_{3}$ gas treatment for the introduction of nitrogen atom to AC surface enhances the ability of activation of dissolved oxygen, causing the increase in the amount of dechlorination.

\section{4 $\mathrm{HNO}_{3}$ oxidation}

The properties of pore structures and elemental composition for
Table 4 Surface functional groups and $\mathrm{pH}_{\mathrm{pzc}}$ of each activated carbon.

\begin{tabular}{cccccc}
\hline & \multicolumn{4}{c}{ Surface functional groups, meq./g } & \\
\cline { 2 - 5 } & Carboxylic & Lactonic & Phenolic & Total basic & \\
\hline F400-DA & 0.07 & 0.09 & 0.27 & 0.31 & 6.7 \\
F400-OG & 0.01 & 0.00 & 0.26 & 0.51 & 9.7 \\
F400-OX & 0.88 & 0.32 & 1.09 & 0.06 & 3.5 \\
\hline
\end{tabular}

F400-OX are shown in Tables 2, 3 and Table 4 gives the surface functional groups and $\mathrm{pH}_{\mathrm{pzc}}$ of F400-DA, F400-OG and F400-OX, respectively. The specific surface area $\left(S_{\alpha \mathrm{s}}\right)$ of $1227 \mathrm{~m}^{2} / \mathrm{g}$ for F400DA was decreased to $951 \mathrm{~m}^{2} / \mathrm{g}$ by $\mathrm{HNO}_{3}$ oxidation, while the inverse trend was observed for $r_{\text {meso }}$ and oxygen content. The decrease in $S_{\alpha \mathrm{s}}$ and the increase in oxygen content are due to the formation of the acidic functional groups which block $\mathrm{N}_{2}$ adsorption in micro pore and cause the decrease in surface area ${ }^{30)}$. On the other hand, the increase in $r_{\alpha \text { meso }}$ is due to the expansion of the micro pore to the meso pore caused by the destruction of the micro pore walls in the oxidation ${ }^{31)}$. The carboxylic, lactonic and phenolic groups which were introduced by $\mathrm{HNO}_{3}$ oxidation increased oxygen content and decreased $\mathrm{pH}_{\mathrm{pzc}}$.

Table 3 shows the influence of $\mathrm{HNO}_{3}$ oxidation on 4-chlorophenol (4-CP) adsorption and dechlorination amount. 4-CP adsorption and dechlorination amount for F400-OX decreased compared to F400DA as a precursor $(p<0.01)$. The decrease in 4-CP adsorption amount (31.5\% lower than F400-DA) is due to the decrease in surface area (23.5\% lower than F400-DA), which would be attributed to the presence of the acidic functional groups. The acidic functional groups 
possessing electron-withdrawing ability decline the $\pi$ electron density of activated carbon (AC) surface and weaken the affinity of adsorbent ${ }^{32)}$. Also, the water cluster formed by the acidic functional groups causes the inhibition of the approach of adsorbates to the adsorption sites $^{33)}$.

The decrease in dechlorination amount for F400-OX compared to F400-DA implies that the activation of dissolved oxygen is inhibited on the F400-OX surface. The similar result was reported by Terzyk et al., who found that the carboxylic groups diminished the oxidative coupling of phenols ${ }^{9}$. The inhibition of activation of dissolved oxygen by $\mathrm{HNO}_{3}$ oxidation would be due to the electron-withdrawing ability of the acidic functional groups, causing the degradation of electron transfer reaction for activation of dissolved oxygen ${ }^{13)}$. This result indicates that the oxidation of AC inhibits the reduction of dissolved oxygen, which would cause the inhibition of dechlorination reaction as observed in this study.

\subsection{Influence of temperature}

Fig. 2 shows dechlorination rate of 4-chlorophenol (4-CP) for F400-OG at different temperature. Dechlorination rate increased with increasing temperature. On the other hand, adsorption of some substituted phenols on activated carbon fiber (ACF) by the $\pi-\pi$ interaction exhibited the exothermic nature ${ }^{3)}$. These results suggest that the increase in dechlorination amount according to the temperature rising did not relate to the change in the amount of 4-CP adsorbed on to activated carbon surface. At all temperature conditions, the dechlorination amount was linearly increased as a function of adsorption time $\left(R^{2}=0.93-0.99\right)$.

The activation energy $\left(E_{\mathrm{a}}\right)$ was evaluated by the Arrhenius equation.

$$
k=A e^{-\frac{E_{\mathrm{a}}}{R T}},
$$

where, $T, A$ and $R$ are the temperature of solution, the pre-exponential factor and the gas constant, respectively. In this study, the rate constant $k$ was defined by following equations.

$$
\begin{aligned}
& \mathrm{AC}+\mathrm{Cl}-\mathrm{C}_{6} \mathrm{H}_{4}-\mathrm{OH} \stackrel{k}{\longrightarrow} \mathrm{AC}^{+}-\mathrm{C}_{6} \mathrm{H}_{4}-\mathrm{OH}+\mathrm{Cl}^{-} \\
& \frac{\mathrm{d}\left[\mathrm{Cl}^{-}\right]}{\mathrm{d} t}=k[\mathrm{AC}]\left[\mathrm{Cl}-\mathrm{C}_{6} \mathrm{H}_{4}-\mathrm{OH}\right] \cong k \quad \ldots \ldots \ldots \ldots . .
\end{aligned}
$$

where, $\left[\mathrm{Cl}^{-}\right]$is the chloride ion concentration in solution, $[\mathrm{AC}]$ and $\left[\mathrm{Cl}-\mathrm{C}_{6} \mathrm{H}_{4}-\mathrm{OH}\right]$ are the amount of activated carbon and 4-CP adsorbed on $\mathrm{AC}$, respectively. In Eq. (12), [AC] is constant. Also, the adsorption rate of 4-CP is enough large compared to the dechlorination rate, therefore, $\left[\mathrm{Cl}-\mathrm{C}_{6} \mathrm{H}_{4}-\mathrm{OH}\right]$ can be regarded as constant. $k$ at each temperature was calculated from the dechlorination rate in Fig. 2. $E_{\mathrm{a}}$ is obtained from the slope of the Arrhenius plot of $\ln k$ versus $1 / T$ as shows in Fig. 3. The value of $E_{\mathrm{a}}$ for dechlorination reaction was calculated as $31.5 \mathrm{~kJ} / \mathrm{mol}$. Grant et al. implied that the carbon-based

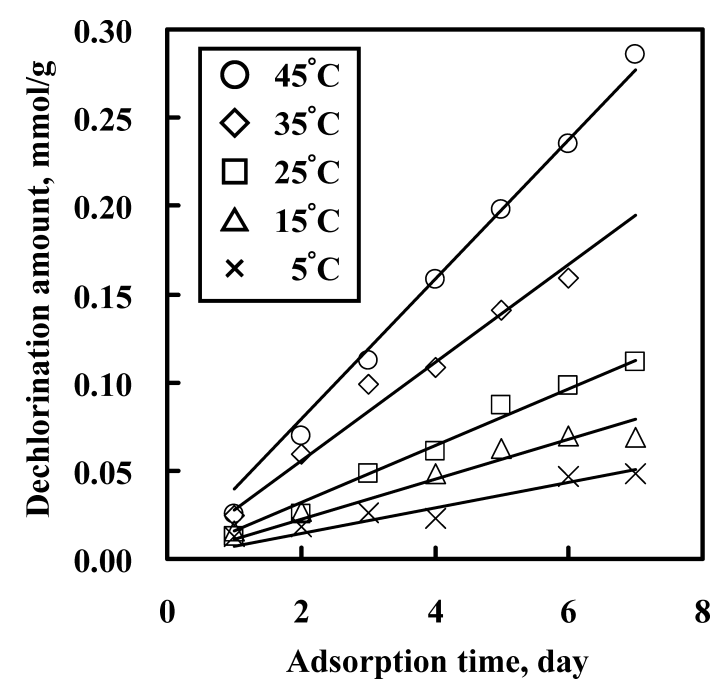

Fig. 2 Dechlorination amounts of 4-CP on F400-OG at different temperature. Initial concentration: $10.0 \mathrm{mmol} / \mathrm{L} . \bigcirc 45^{\circ} \mathrm{C}$, $\diamond 35^{\circ} \mathrm{C}, \square 25^{\circ} \mathrm{C}, \triangle 15^{\circ} \mathrm{C}, \times 5^{\circ} \mathrm{C}$.

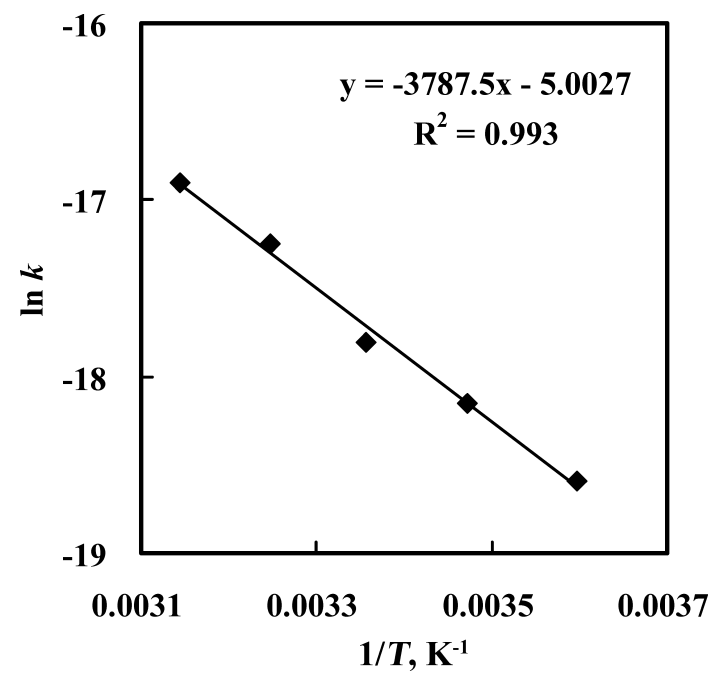

Fig. 3 Arrhenius plot on dechlorination rate $(k)$ at different temperature $(T)$.

catalyst would represent a high activation energy compared with $\mathrm{CuCl}$ catalyst $(12.5 \mathrm{~kJ} / \mathrm{mol})$ in the oxidative coupling of phenol ${ }^{4}$. Their finding supports the result of $E_{\mathrm{a}}$ value obtained in this study.

\section{Conclusion}

In this study, the effect of various parameters was investigated for the clarification of oxidative coupling and dechlorination reaction mechanism for chlorophenol. The main conclusions can be summarized as follows.

(1) Under anoxic conditions, the dechlorination reactions of mono-chlorophenols (mono-CPs) were inhibited. Dissolved oxygen was reduced to reactive oxygen species on the activated carbon (AC) surface. Reactive oxygen species reacted with mono-CPs and caused the oxidative coupling and dechlorination reaction via phenoxyl radical.

(2) The difference in the dechlorination amount for different ad- 
sorbates was explained with the difference of the covalent binding site between adsorbate and AC. 4-Chlorophenol bound with AC at para position and showed the highest dechlorination amount, whereas 3-chlorophenol (3-CP) was affected by the steric barrier of chloride atom and the unpaired electron of free radical was not located at a chlorine-substituted position. Therefore, 3-CP showed the lowest reactivity to the dechlorination reaction.

(3) The $\mathrm{NH}_{3}$ gas-treated $\mathrm{AC}$ leading to the predominance of pyrrol- and/or pyridine-like surface species promoted the activation of dissolved oxygen compared to the original AC. On the other hand, the $\mathrm{HNO}_{3}$ oxidized $\mathrm{AC}$ with the acidic functional groups prevented the activation of dissolved oxygen. These results indicated that the electron transfer ability of AC played a key role in the activation of dissolved oxygen, consecutive oxidative coupling and dechlorination reaction

(4) Activation energy of the dechlorination reaction was calculated as $31.5 \mathrm{~kJ} / \mathrm{mol}$ from the measurement of dechlorination rate at different temperature.

\section{Acknowledgements}

This study was funded in part by the Japan Society for the Promotion of Science (JSPS) under Grants-in-Aid for Scientific Research (C) (No. 23510091). The authors wish to express gratitude to Prof. Dr. Keiichi Nagao, Head of Safety and Health Organization, Chiba University, for his encouragement and support on this work.

\section{References}

1) C. S. Evans and B. Dellinger, Environ. Sci. Technol. 39 (2005) 122-127.

2) E. G. Furuya, H. T. Chang, Y. Miura and K. E. Noll, Separ. Purif. Tech. 11 (1997) 69-78.

3) Q.-S. Liu, T. Zheng, P. Wang, J.-P. Jiang and N. Li, Chem. Eng. J. 157 (2010) 348-356.

4) T. M. Grant and C. J. King, Ind. Eng. Chem. Res. 29 (1990) 264-271.

5) R. D. Vidic, M. T. Suidan and R. C. Brenner, Environ. Sci. Technol. 27 (1993) 2079-2085.

6) N. A. Zeid, G. Nakhla, S. Farooq and E. Osei-Twum, Water Res. 29 (1995) 653-660.
7) R. D. Vidic, C. H. Tessmer and L. J. Uranowski, Carbon 35 (1997) 1349 1359.

8) A. C. O. Pimenta and J. E. Kilduff, J. Colloid Interface Sci. 293 (2006) 278-289.

9) A. P. Terzyk, Appl. Surf. Sci. 253 (2007) 5752-5755.

10) Q. Lu and G. A. Sorial, J. Hazard. Mater. 148 (2007) 436-445.

11) J. Jinag, S.-Y. Pang and J. Ma, Carbon 47 (2009) 2115-2117.

12) B. Stöhr, H. P. Boehm and R. Schlögl, Carbon 29 (1991) 707-720.

13) V. V. Strelko, N. T. Kartel, I. N. Dukhno, V. S. Kuts, R. B. Clarkson and B. M. Odintsov, Surf. Sci. 548 (2004) 281-290.

14) N. V. Vorob'ev-Desyatovskii, R. I. Ibragimova, S. K. Gordeev and B. P. Nikolaev, Russ. J. Gen. Chem. 76 (2006) 946-954.

15) M. P. Woods, E. J. Biddinger, P. H. Matter, B. M. Mirkelamoglu and U. S. Ozkan, Catal. Lett. 136 (2010) 1-8.

16) H. Niwa, M. Kobayashi, K. Horiba, Y. Harada, M. Oshima, K. Terakura, T. Ikeda, Y. Koshigoe, J. Okazaki, S. Miyata, S. Ueda, Y. Yamashita, H. Yoshikawa and K. Kobayashi, J. Power Sources 196 (2011) 1006-1011.

17) C. L. Mangun, K. R. Benak, J. Economy and K. L. Foster, Carbon 39 (2001) 1809-1820

18) K. Kaneko, C. Ishii, M. Ruike and H. Kuwabara, Carbon 30 (1992) 1075-1088.

19) K. Kaneko and C. Ishii, Colloids Surf. 67 (1992) 203-212.

20) H. P. Boehm, Carbon 40 (2002) 145-149.

21) J. S. Noh and J. A. Schwarz, Carbon 28 (1990) 675-682.

22) E. Mvula and C. von Sonntag, Org. Biomol. Chem. 1 (2003) 1749-1756

23) J. Dec and J. M. Bollag, Environ. Sci. Technol. 28 (1994) 484-490.

24) F. G. Bordwell and J. Cheng, J. Am. Chem. Soc. 113 (1991) 1736-1743.

25) M. M. Maroto-Valer, I. Dranca, D. Clifford, T. Lupascu, R. Nastas and C. A. Leon y Leon, Thermochim. Acta 444 (2006) 148-156.

26) M. Katsura, K. Nishimaki, T. Nakagawa, T. A. Yamamoto, M. Hirota and M. Miyake, J. Nucl. Mater. 258-263 (1998) 839-842.

27) M. S. Shafeeyan, W. M. A. W. Daud, A. Houshmand and A. Shamiri, J. Anal. Appl. Pyrolysis 89 (2010) 143-151.

28) A. Aworn, P. Thiravetyan and W. Nakbanpote, J. Anal. Appl. Pyrolysis $\mathbf{8 2}$ (2008) 279-285

29) R. J. J. Jansen and H. van Bekkum, Carbon 33 (1995) 1021-1027.

30) J.-W. Shim, S.-J. Park and S.-K. Ryu, Carbon 39 (2001) 1635-1642.

31) C. Moreno-castilla, F. Carrasco-marín, F. J. Maldonado-hódar and J. Rivera-utrilla, Carbon 36 (1998) 145-151.

32) I. I. Salame and T. J. Bandosz, J. Colloid Interface Sci. 264 (2003) $307-$ 312 .

33) Y. Kato, M. Machida and H. Tatsumoto, J. Colloid Interface Sci. 322 (2008) 394-398. 